\title{
Effect of salinity on the uptake of cadmium by the brine shrimp Artemia franciscana
}

\author{
Ronny Blust, Eva Kockelbergh, Marc Baillieul
}

Department of Biology, University of Antwerp. (RUCA), Groenenborgerlaan 171, B-2020 Antwerpen, Belgium

\begin{abstract}
The effect of salinity on cadmium uptake by brine shrimp Artemia franciscana was studied in chemically defined saltwater solutions. Shrimp were acclimated to different salinities and exposed to the metal in solutions of differing salinity and composition. Within each acclimation group, the cadmium uptake decreased with increasing salinity of exposure. Most of this variation was explained by changes in the activity of the free metal ion. Among the acclimation groups, uptake increased with increasing salinity of acclimation. Most of this variation was explained by changes in the permeability of the shrimp. Uptake was not influenced by changes in the osmolarity or the concentration of any of the major cations in the solution. The integration of both chemical and biological effects of changes in salinity explains almost all variation in cadmium uptake by brine shrimp.
\end{abstract}

\section{INTRODUCTION}

The uptake and accumulation of cadmium by aquatic organisms is a long-standing environmental problem (Nriagu 1988, Nriagu \& Pacyna 1988). The chemical speciation of cadmium in saline waters with a composition similar to that of seawater is dominated by the formation of weak complexes with chloride. Only a small fraction of the cadmium exists as the free metal ion while most of the cadmium is found in chloride complexes. In dilute solutions chloride complexation becomes less and less important and the concentration of the free metal ion increases with decreasing salinity (Boyle et al. 1976, Mantoura et al. 1978, Turner et al. 1981).

Cadmium has no known biological function and the internal body concentration is not regulated (Wright 1977a, Dethlefsen 1978, White \& Rainbow 1982, 1986. Rainbow 1985). The availability of cadmium to aquatic organisms is determined by a number of environmental factors of which change in salinity is one of the most important.

Aquatic organisms control the movement of water and ions across the exchange surfaces by altering the permeability of the body surface and/or by actively regulating the influx and efflux of water and ions. Acclimation of an aquatic organism to salinity involves the alteration of the exchange surfaces (e.g. gill and gut epithelium) in order to maintain the composition of the internal environment within certain physiological limits. Generally, the permeability of aquatic organisms is lower in low salinity than in high salinity environments. These physiological alterations in response to changes in salinity have profound effects on the movement of water and ions across the exchange surfaces (Gilles \& Pequeux 1983, Mantel \& Farmer 1983).

Several studies have shown an inverse relationship between the salinity and the uptake or toxicity of cadmium in aquatic organisms. This observation has been explained in different ways including: (1) increased availability of cadmium at low salinity caused by the increased free cadmium ion level (Sunda et al. 1978, Engel \& Fowler 1979, De Lisle \& Roberts 1988), (2) increased influx of cadmium as a result of the decreased osmolarity of the solution (George et al. 1978), and (3) competition of calcium and magnesium with cadmium for similar uptake sites (Wright $1977 \mathrm{~b}$, Wright \& Frain 1981, Pärt et al. 1985).

The functionally different, but compatible, explanations for the effect of salinity on the uptake of cadmium by aquatic organisms have created considerable controversy concerning the processes controlling the transport of the metal across the solution-body interface. To understand how these chemical and biological processes influence the availability of cadmium to saltwater organisms it is necessary to determine the sepa- 
rate and combined effects of these different salinity components on metal uptake. For this purpose we have studied the effect of changes in salinity on the uptake of cadmium by the euryhaline brine shrimp Artemia franciscana in relation to the effects of salinity on the chemical speciation of the metal, the osmolarity and the concentrations of any of the major cations in the solution.

\section{MATERIALS AND METHODS}

Brine shrimp. Dried Artemia franciscana cysts from Great Salt Lake, Utah, USA, were purchased from San Francisco Bay Brand, Newark, CA, USA. Cysts were hatched in a funnel-shaped plastic container filled with synthetic seawater (Wiegandt, Krefeld, Germany), and aerated from the bottom. The hatching suspension was illuminated by a fluorescent light tube. Hatching cyst density was $5 \mathrm{~g} \mathrm{l}^{-1}$. Artemia franciscana nauplii were harvested after $36 \mathrm{~h}$. The larvae were grown from nauplii to adult in $150 \mathrm{I}$ plastic rectangular air-water lift-operated raceways filled with synthetic seawater. Brine shrimp were fed with a suspension of the dried algae Spirulina sp. Shrimp reached maturity after 3 to $4 \mathrm{wk}$ and were used before they were $8 \mathrm{wk}$ old. The methods for intensive culturing of brine shrimp have been described by Sorgeloos et al. (1983)

Experimental procedures. Accumulation of cadmium during $3 \mathrm{~h}$ of exposure was used as a measure for biological availability of the metal. Experiments were conducted in a thermostated room at $25.0 \pm$ $0.5^{\circ} \mathrm{C}$. Fifteen days before an experiment was run adult brine shrimp were collected from a batch culture for salinity acclimation. They were gradually acclimated to chemically defined solutions of differing salinity over a $5 \mathrm{~d}$ period and kept at the final salinity for the remaining $10 \mathrm{~d}$ (i.e. $0.5,1.0,2.0,3.0,4.0 \%$ ). On the last day of the acclimation period shrimp were transferred for $1 \mathrm{~h}$ to a saltwater solution containing $1 \mathrm{mM}$ of 8-hydroxyquinoline-5-sulfonic acid. This strong metal ligand, which is not acutely toxic to brine shrimp, was used to remove metal bound to the external surfaces of the shrimp. For the remaining period the shrimp were kept in clean saltwater to clear their gut. The composition of $1 \mathrm{l}$ of the chemically defined saltwater solution with a salinity of $4.0 \%$ was $26.85 \mathrm{~g}$ $\mathrm{NaCl}, 4.57 \mathrm{~g} \mathrm{Na}_{2} \mathrm{SO}_{4}, 0.777 \mathrm{~g} \mathrm{KCl}, 0.196 \mathrm{~g} \mathrm{NaHCO}_{3}$, $1.68 \mathrm{~g} \mathrm{CaCl}_{2} \cdot 2 \mathrm{H}_{2} \mathrm{O}, 12.32 \mathrm{~g} \mathrm{MgCl}_{2} \cdot 6 \mathrm{H}_{2} \mathrm{O}$ and $0.026 \mathrm{~g}$ $\mathrm{H}_{3} \mathrm{BO}_{3}$. The medium was prepared by dissolving the 7 analytical grade products (Merck p.a.) in deionised water. A dispersion of $0.1 \mathrm{mmol} \mathrm{l}^{-1}$ manganese dioxide was added to the seawater to remove metals present in the analytical grade reagents. After an equilibration period of $24 \mathrm{~h}$, the dispersion was filtered through a $0.2 \mu \mathrm{m}$ membrane filter to remove the manganese dioxide from the solution (Van den Berg \& Kramer 1979). Solutions of lower salinity were prepared by dilution of the $4.0 \%$ solution with deionised water. In some series of experiments the metal chloride salts were totally or partially replaced by nitrate salts which do not complex cadmium. In one of these experiments the osmolarity of the solution was controlled by addition of sucrose to the solutions. The osmolarity of the solutions was measured with an osmometer which was calibrated with a stock solution of sodium perchlorate (Advanced Instruments Laboratory osmometer).

The $\mathrm{pH}$ of the solutions was adjusted with $\mathrm{HCl}$ or $\mathrm{NaOH}$ as required and the media were aerated to promote equilibration of gases with the atmosphere. The dissolved oxygen concentration, the total dissolved carbonate concentration, the hydrogen ion activity and the redox potential were measured to ensure that equilibrium conditions had been established. Dissolved oxygen was measured with a polarographic oxygen electrode system (WTW OX191/EO90). Total dissolved carbon dioxide was measured with a gas-sensing $\mathrm{CO}_{2}$ electrode (Ingold 152323000), after acidification of the water sample $(\mathrm{pH}<4.8)$ in a sealed measuring vessel. The hydrogen ion activity was measured with a glass electrode (Ingold 104573002), and $\mathrm{pH}$ values expressed on a free hydrogen ion scale (Millero 1986). Redox potentials were measured with a wire type platinum electrode (Ingold 105003077). Cadmium nitrate was added to the test solutions from a $0.1 \mathrm{mmol} \mathrm{l}^{-1}$ cadmium ion stock. In all series of experiments the total concentration of cadmium in the test solutions was $100 \mu \mathrm{mol} \mathrm{l}^{-1}$. Experiments were carried out in 0.51 plastic beakers. Just before an experiment started ca 50 shrimp were collected on a $250 \mu \mathrm{m}$ screen, rinsed with clean medium, and transferred to a beaker. After 180 min the beaker was removed and a few $\mathrm{ml}$ of the test solution were placed in a plastic vial and stored frozen at $-20^{\circ} \mathrm{C}$ until analysed for cadmium. The beaker was subsequently emptied over a $250 \mu \mathrm{m}$ screen. The collected shrimp were rinsed with deionised water and divided into 5 plastic vials, dried for $24 \mathrm{~h}$ at $60^{\circ} \mathrm{C}$ and stored in a dessication box until analysed for cadmium. All experiments were run at least in duplicate using brine shrimp from different batch cultures. For each treatment group 5 replicate samples were obtained. The dissolved oxygen concentration, the total dissolved carbonate concentration, the hydrogen ion activity, the redox potential and the total dissolved cadmium concentration were measured at the beginning and end of an experiment Generally, all measured values remained within $10 \%$ of the initial values.

Chemical modelling and ion selective potentiometry. The equilibrium concentrations of the chemical species 
considered were calculated using the computer program SOLUTION (Blust et al. unpubl.), an adaptation of the program COMPLEX (Ginzburg 1976). This speciation model allows the calculation of the composition of solutions in equilibrium with gas and solid phases. The model uses the ion-association concept which invokes the existence of molecular species like free ions, ionpairs and complexes. A thermodynamic stability constant data base was built based on the data of Dickson \& Whitfield (1981) for the major components and the data of Smith \& Martell $(1976,1989)$ and Martell \& Smith (1982) for cadmium. For each ion-pair or complex species considered the stability constants listed for different ionic strengths were fitted to an interpolation function that has the form of an extended Debye-Hückel equation (Turner et al. 1981). Activity coefficients were calculated using the relations given by Millero \& Schreiber (1982). The redox potential of the solutions was calculated from the empirical relation $\mathrm{pE}=17.6$ $\mathrm{pH}$ (Baas-Becking et al. 1960). The thermodynamic stability constants and concentration products at the ionic strength of the saltwater solution for all cadmium species included in the model are given in Table 1. Case-specific input comprises the total concentrations of the metals and ligands in the solution, the free hydrogen concentration $(\mathrm{pH})$, redox potential $(\mathrm{pE})$, temperature, and the gas and solid phases that are maintained in equilibrium with the solution.

The results of the speciation calculations were verified by measuring the free cadmium ion concentration with a cadmium ion electrode (Orion Model 94-48). The electrode was calibrated for the range 0.1 to $10000 \mu \mathrm{M}$ free cadmium and 0.01 to $1 \mathrm{M}$ ionic strength. Sodium perchlorate was used as the background electrolyte for these calibrations.

Metal analysis. Cadmium was measured by graphite furnace atomic absorption spectrophotometry using a Perkin-Elmer 703 spectrophotometer fitted with a heated graphite atomiser HGA-500 and a deuterium arc

Table 1 Thermodynamic stability constants and concentration products for cadmium species. $K$ : thermodynamic stability constant, $Q$ : concentration products at salinity $0.5 \%$ and $4.0 \%$

\begin{tabular}{|lccc|}
\hline Species & Log $K$ & $\begin{array}{c}\log Q \\
(S=0.5 \%)\end{array}$ & $\begin{array}{c}\text { Log } Q \\
(\mathrm{~S}=4.0 \%)\end{array}$ \\
\hline $\mathrm{Cd}^{2+}$ & - & - & - \\
$\mathrm{CdCl}^{+}$ & 1.97 & 1.56 & 1.35 \\
$\mathrm{CdCl}_{2}{ }^{0}$ & 2.59 & 1.98 & 1.70 \\
$\mathrm{CdCl}_{3}{ }^{-}$ & 2.40 & 1.76 & 1.48 \\
$\mathrm{CdCl}_{4}{ }^{2-}$ & 1.47 & 1.22 & 1.38 \\
$\mathrm{CdSO}_{4}{ }^{0}$ & 2.45 & 1.62 & 1.04 \\
$\mathrm{Cd}\left(\mathrm{SO}_{4}\right)_{2}{ }^{2-}$ & 3.44 & 2.58 & 1.83 \\
$\mathrm{CdOH}{ }^{+}$ & 3.91 & 3.49 & 3.33 \\
$\mathrm{Cd}(\mathrm{OH})_{2}{ }^{0}$ & 7.64 & 7.01 & 6.75 \\
$\mathrm{CdCO}{ }^{0}$ & 4.35 & 3.52 & 2.94 \\
\hline
\end{tabular}

background corrector The method of stabilised temperature platform atomisation was used (Slavin et al. 1983). Biological material was dissolved with concentrated nitric acid in a microwave oven and diluted with deionised water to a $10 \%$ nitric acid solution. Saltwater solutions were diluted 10 times with a $10 \%$ nitric acid solution to decrease the salinity. Matrix modificator $\left[200 \mu \mathrm{g}\left(\mathrm{NH}_{4}\right)_{2} \mathrm{HPO}_{4}+20 \mu \mathrm{g} \mathrm{Mg}\left(\mathrm{NO}_{3}\right)_{2}\right.$ per sample] was added to the solutions and they were analysed against matrix matched calibration standards (Blust et al. 1988).

Statistical analysis. All sets of data were tested for homogeneity of variances by the log-anova test and for normality by the Kolmogorov-Smirnov test for goodness of fit. Analysis of variance, single and multiple linear regression, and non-linear regression methods were used for analysing the data. The $T$-method was used to make multiple comparisons among pairs of means with homogeneous variances. The Games \& Howell method was used to make multiple comparisons among pairs of means with heterogeneous variances. Significance levels of tests are indicated by asterisks according to the following probability ranges: $\cdot 0.05 \geq p>0.01, \cdots 0.01 \geq p>0.001, \cdots p \leq 0.001$. Statistical methods used are outlined in Sokal \& Rohlf (1981) and Glantz \& Slinker (1990).

\section{RESULTS}

\section{Chemical speciation of cadmium}

The complexation of cadmium in a chemically defined saltwater solution that does not contain organic ligands is controlled by the concentration of chloride. Changes in the hydroxide and carbonate concentration do not alter the speciation of the metal considerably. The calculations and measurements of the free metal ion concentration are in good agreement. The free metal ion is a minor species in waters of high salinity and a major species in waters of low salinity. With increasing salinity the difference between the concentration and activity of the cadmium ion becomes increasingly important. The results of the model calculations and the ion selective electrode measurements concerning the effect of salinity on the speciation of cadmium are summarised in Figs. 1 \& 2 .

\section{Salinity acclimation and cadmium uptake}

To determine the effect of the salinity of acclimation and salinity of exposure on the uptake of cadmium by brine shrimp, 5 groups of organisms were acclimated to 5 different salinities during a $14 \mathrm{~d}$ period (i.e. 0.5 , $1.0,2.0,3.0$ and $4.0 \%$ ). After the acclimation period 


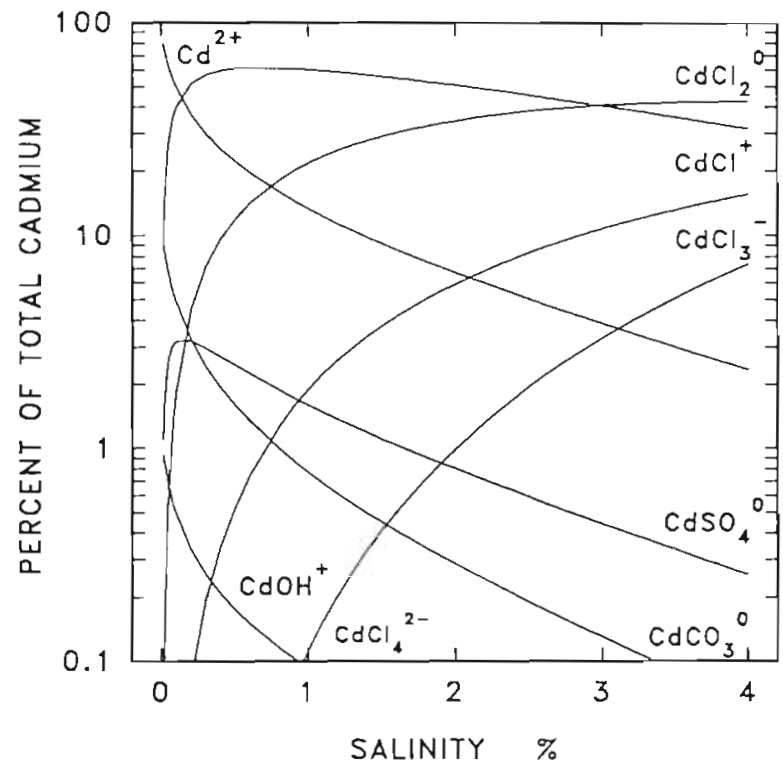

Fig. 1 Speciation model of cadmium as a function of the salinity of the solution $\left(\mathrm{pH}=8.1, \mathrm{pO}_{2}=10^{-0.69}\right.$ atm, $\mathrm{pCO}_{2}=$ $10^{-3.48}$ atm)

organisms from each group were transferred for $3 \mathrm{~h}$ to solutions of differing salinity (i.e. $0.1,0.2,0.3,0.4,0.5$, $1.0,1.5,2.0,2.5,3.0,3.5$, and $4.0 \%$ ) to which $100 \mu \mathrm{M}$ of cadmium was added. For each of the 5 different acclimation groups the uptake of cadmium decreased rapidly with increasing salinity of exposure but there were marked differences among the acclimation

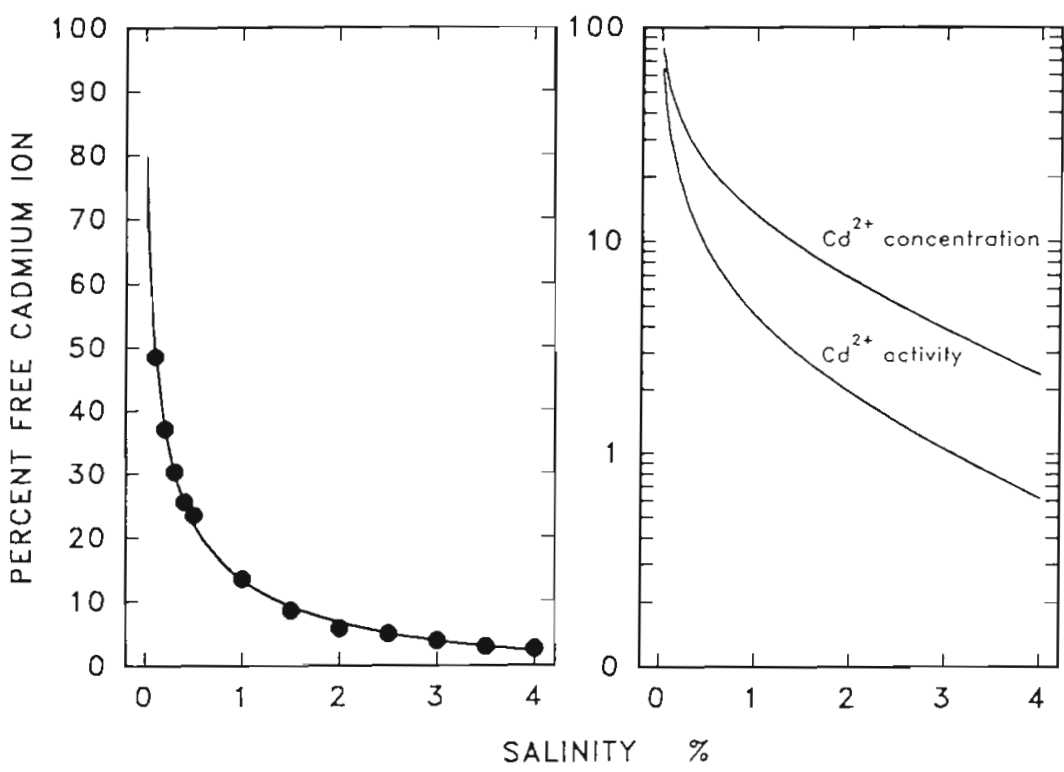

Fig. 2. (a) Free cadmium ion concentration as a function of the salinity of the solution. (-) Measured free cadmium ion concentrations; solid line: modelled free cadmium ion concentration $\left(\mathrm{pH}=8.0\right.$ to $8.2, \mathrm{pO}_{2}=10^{-0.69} \mathrm{~atm}, \mathrm{pCO}_{2}=$ $10^{-348} \mathrm{~atm}$ ). (b) Modelled free cadmium ion concentration and activity as a function of the salinity of the solution $\left(\mathrm{pH}=8.1, \mathrm{pO}_{2}=10^{-0.69} \mathrm{~atm}, \mathrm{pCO}_{2}=10^{-3.48} \mathrm{~atm}\right)$ groups. For the same salinity of exposure, uptake of cadmium increased with increasing salinity of acclimation. The results of the experiments with the 0.5 and $4.0 \%$ acclimation groups are summarised in Fig. 3 These results are representative for the results obtained with the other acclimation groups. The results of the correlation analysis summarised in Table 2 show that there is always a highly significant correlation between the change in salinity (and the covarying factors such as the ionic strength and osmolarity of the solution), changes in the activity or concentration of the free metal ion, and the uptake of cadmium by the brine shrimp. The results summarised in Fig. 4 show that uptake of cadmium by brine shrimp exposed to the salinity of acclimation decreased with increasing salinity.

\section{Salinity components and cadmium uptake}

To determine and separate the effects of the different salinity components (i.e. changes in metal speciation, solution osmolarity and composition) on the uptake of cadmium by brine shrimp, different experiments were performed using specimens acclimated to a salinity of either 0.5 or $4.0 \%$.

To determine the effect of complexation on uptake, shrimp were exposed to solutions with different chloride concentrations in which the salinity was kept constant by replacing chloride with nitrate. Complexation of cadmium with nitrate is neglible so that replacement of chloride with nitrate increases free metal ion activity or concentration while salinity of the solution remains constant. The results summarised in Fig. 5 show that complex formation decreased cadmium uptake in both the low and high salinity acclimation groups. In both cases the linear association between changes in the concentration or covarying activity of the free metal ion and uptake of cadmium is highly significant (salinity $0.5 \%$ $r^{2}=0.792 \cdots, n=7$; salinity $4.0 \%$, $r^{2}=0.987 \cdots, n=14$ ). Comparison of the results of the effect of changes in salinity (Fig 3) with the results of changes in chloride concentration at constant salinity (Fig. 5) show that not all of the variation in metal uptake with salinity is explained by the complexation effect.

To determine the effect of the ionic strength and osmolarity of the solution on the uptake of cadmium, shrimp were exposed to solutions of differing 


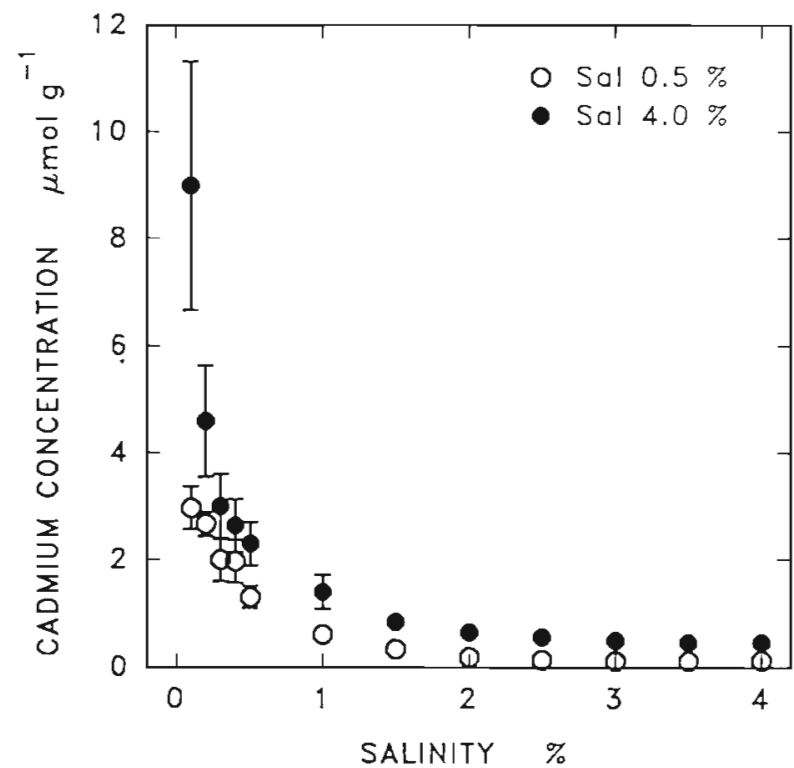

Fig. 3. Artemia franciscana. Effect of the salinity of exposure in a chloride-dominated solution on uptake of cadmium over a $3 \mathrm{~h}$ period for the 0.5 and $4.0 \%$ acclimation groups $\left[\mathrm{Cd}_{\mathrm{T}}=\right.$ $100 \mu \mathrm{M}, \mathrm{pH}=8.0$ to $8.2, \mathrm{pO}_{2}=10^{-0.69} \mathrm{~atm}, \mathrm{pCO}_{2}=10^{-3.48} \mathrm{~atm}$ solution contains chloride). Means with SD for 5 replicates are significantly different for both the 0.5 and $4.0 \%$ groups, $\mathrm{p}<0.01$

salinity with very low complexation capacity. For this purpose all chloride was replaced with nitrate. Under these conditions the concentration of the free metal ion is close to the total metal concentration ( 80 to $90 \%$ ) and does not vary appreciably with salinity. However, since the activity of the free metal ion depends on the ionic strength of the solution, the activity and concentration of the free metal ion do not covary under these circumstances. In half of these experiments sucrose was used as an osmolyte to keep the osmolarity the same as the osmolarity of the solutions of acclimation. The results summarised in Figs. $6 \& 7$ show that the uptake of cadmium decreases with increasing salinity in both the low and high salinity group and that this effect does not depend on the osmolarity of the solution. In both cases the linear association between changes in the activity of the free metal ion and the uptake of cadmium is always better than the association between changes in the concentration of the free metal ion and the uptake of cadmium (salinity $0.5 \%$ : nitrate, $\mathrm{Cd}^{2+}$ act $\mathrm{r}^{2}=0.760 \cdots$, $\mathrm{Cd}^{2+}{ }_{\text {conc }} \mathrm{r}^{2}=0.089^{\text {ns }}, \mathrm{n}=13$; sucrose, $\mathrm{r}^{2}=0.927 \cdots, \mathrm{r}^{2}=$ $0.727^{\circ}, \mathrm{n}=6$; salinity $4.0 \%$ : nitrate, $\mathrm{r}^{2}=0.979 \%$, $r^{2}=0.414^{\circ}, n=13$; sucrose, $r^{2}=0.872 \cdots, r^{2}=0.253^{\circ}$, $\mathrm{n}=13$ ).

To determine the effect of changes in the concentration of sodium, potassium, calcium and magnesium and combinations of either sodium and potassium or calcium and magnesium on the uptake of cadmium,
Table 2. Artemia franciscana. Linear coefficients of determination $\left(r^{2}, n=12\right)$ between salinity, free cadmium ion activity or free cadmium ion concentration and cadmium uptake by brine shrimp in different salinity groups

\begin{tabular}{|c|c|c|c|c|c|}
\hline & $0.5 \%$ & $1.0 \%$ & $\begin{array}{l}\text { Salinity } \\
2.0 \%\end{array}$ & $3.0 \%$ & $4.0 \%$ \\
\hline \multicolumn{6}{|c|}{ Uptake and: } \\
\hline Salinity & $0.540^{\circ}$ & $0.480^{\circ}$ & $0.549^{\circ}$ & $0.596^{\circ}$ & $0.502^{\cdots}$ \\
\hline $\mathrm{Cd}^{2+} \mathrm{act}^{2}$ & $0.932 \cdots$ & $0.966^{\cdots}$ & $0.990 \cdots$ & $0.998 \cdots$ & $0.968 \cdots$ \\
\hline $\mathrm{Cd}^{2+}$ rone & $0.969 \cdots$ & $0.935 \cdots$ & $0.955 \cdots$ & $0.965 \cdots$ & $0.900 \cdots$ \\
\hline \multicolumn{6}{|c|}{$\cdots 0.01 \geq p>0.001 ; \cdots p \leq 0.001$} \\
\hline
\end{tabular}

shrimp were exposed to solutions of differing cation composition and constant salinity. For preparation of these solutions the concentration of the salts was altered so that the speciation of cadmium and the osmolarity of the solution remained constant. The results summarised in Fig. 8 show that changes in the concentration of calcium do not influence the uptake of cadmium in both salinity groups. Similar results were obtained with all other major cations either tested separately or in combination

\section{Modelling of cadmium uptake}

Together these results show that 3 factors are important in determining the availability of cadmium to

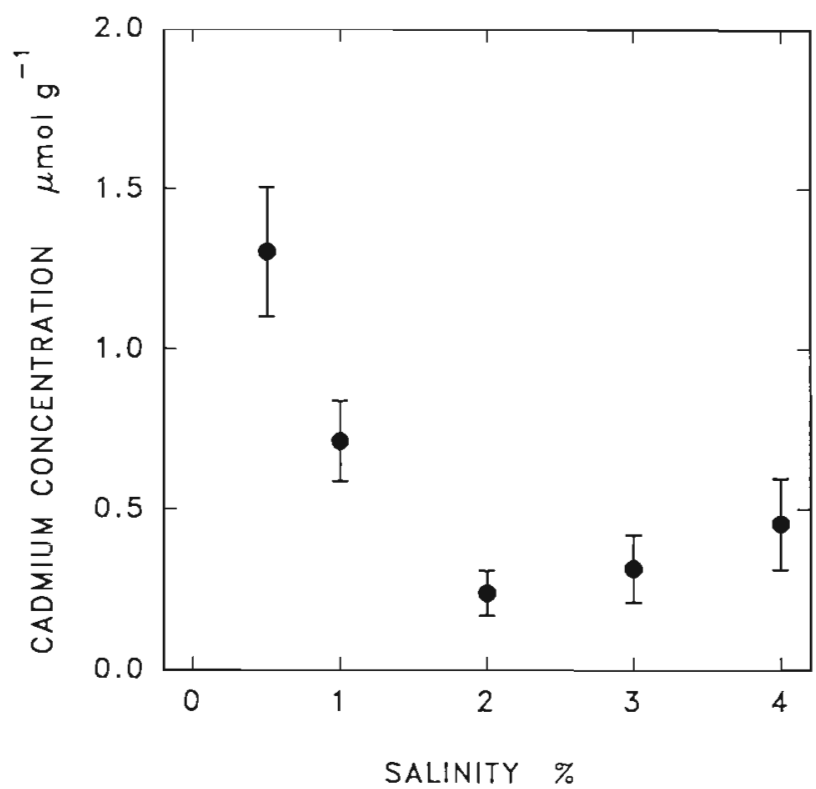

Fig. 4. Artemia franciscana. Effect of the salinity of acclimation on uptake of cadmium over a $3 \mathrm{~h}$ period for the $0.5,1.0$, $2.0,3.0,4.0 \%$ acclimation groups $\left(\mathrm{Cd}_{\mathrm{T}}=100 \mu \mathrm{M}, \mathrm{pH}=8.0\right.$ to 8.2. $\left.\mathrm{pO}_{2}=10^{-6,69} \mathrm{~atm}, \mathrm{pCO}_{2}=10^{-3.48} \mathrm{~atm}\right)$. Means with $\mathrm{SD}$ for 5 replicates are significantly different, $p<0.01$ 


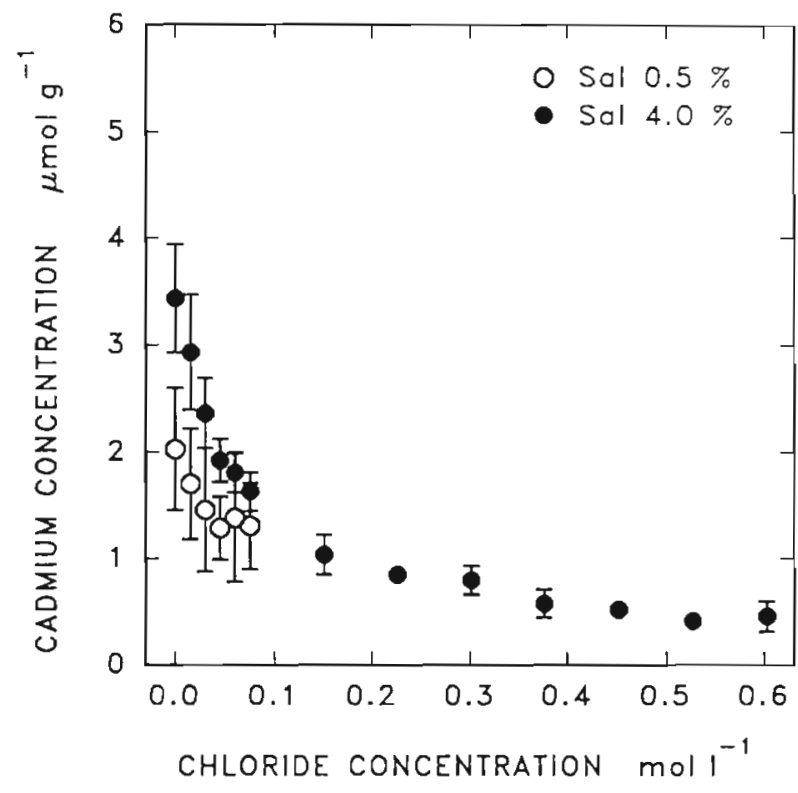

Fig. 5. Artemia franciscana. Effect of chloride at constant salinity of exposure on the uptake of cadmium over a $3 \mathrm{~h}$ period for the 0.5 and $4.0 \%$ acclimation groups $\left(\mathrm{Cd}_{\mathrm{T}}=\right.$ $100 \mu \mathrm{M}_{1} \mathrm{pH}=8.0$ to $8.2, \mathrm{pO}_{2}=10^{-0.69} \mathrm{~atm}, \mathrm{pCO}_{2}=$ $10^{-3.48} \mathrm{~atm}$, solution contains chloride and nitrate). Means with $\mathrm{SD}$ for 5 replicates are not significantly different for the $0.5 \%$ group, $p>0.05$, and significantly different for the $4.0 \%$ group, $p<0.01$

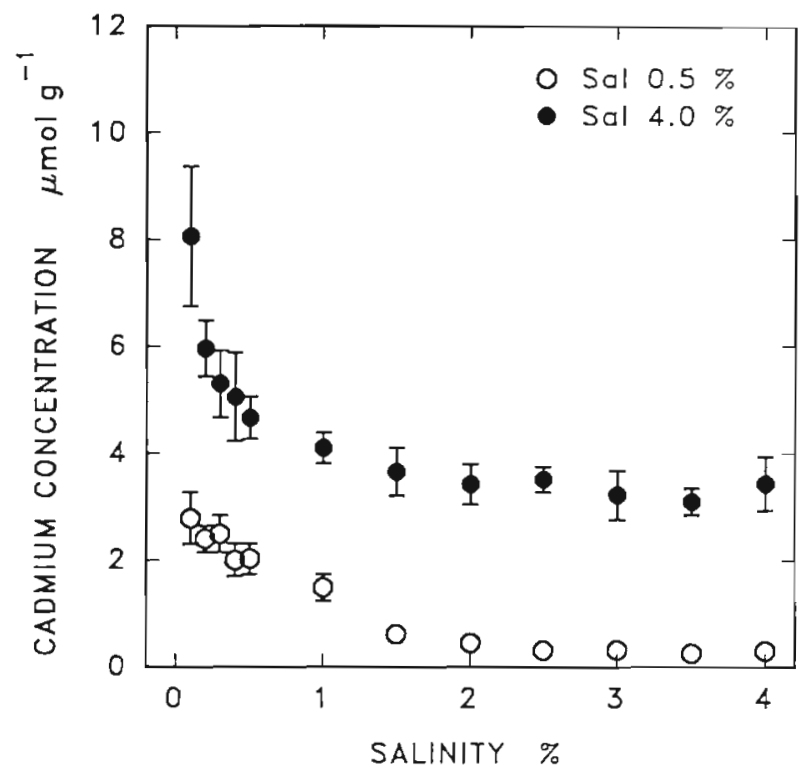

Fig. 6. Artemia franciscana. Effect of the salinity of exposure in a nitrate-dominated solution on the uptake of cadmium over a $3 \mathrm{~h}$ period for the 0.5 and $40 \%$ acclimation groups $\left(\mathrm{Cd}_{\bar{T}}=100 \mu \mathrm{M}, \mathrm{pH}=8.0\right.$ to $8.2, \mathrm{pO}_{2}=10^{-0.69} \mathrm{~atm}$, $\left.\mathrm{pCO}_{2}=10^{-3.48} \mathrm{~atm}\right)$. Means with $\mathrm{SD}$ for 5 replicates are significantly different for both the 0.5 and $4.0 \%$ groups, $\mathrm{p}<0.01$

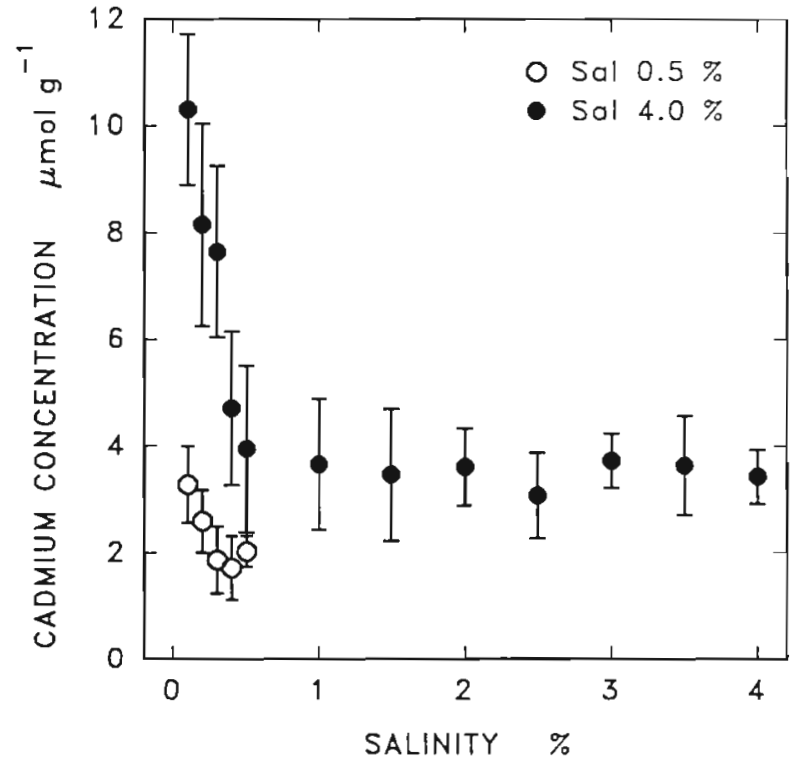

Fig. 7 Artemia tranciscana. Effect of the salinity of exposure at constant osmolarity on the uptake of cadmium over a $3 \mathrm{~h}$ period for the 0.5 and $4.0 \%$ accilimation groups $/ \mathrm{Cd}_{\mathrm{T}}$ $=100 \mu \mathrm{M}, \mathrm{pH}=8.0$ to $8.2, \mathrm{pO}_{2}=10^{-0.59} \mathrm{~atm}, \mathrm{pCO}_{2}=$ $10^{-348} \mathrm{~atm}$, solution contains nitrate and sucrose). Means with SD for 5 replicates are not significantly different for the $0.5 \%$ group, $p>0.05$, and significantly different for the $4.0 \%$ group, $\mathrm{p}<0.01$

brine shrimp. There is the effect of changes in the activity of the free cadmium ion with changes in salinity and there are the effects of the salinity of acclimation and exposure on the translocation of the metal across the solution-body interface.

Metal influx does not increase linearly with the activity of the free cadmium ion over the entire range of activities. However, the decrease in metal uptake at the highest free metal ion levels is reasonably well described by a simple $n$ th-order power reaction rate equation (i.e. simple Michaelis behaviour). Likewise, the effect of the salinity of acclimation and the effect of the salinity of exposure on metal uptake can be described by the product of 2 nth-order power equations. Metal influx is then proportional to the product of the terms describing the effect of the variation in the free metal ion activity, the salinity of exposure and the salinity of acclimation (i.e. $\mathrm{Cd}^{2+}{ }^{2+c^{k}} \cdot \mathrm{Sal}_{\exp }{ }^{1}$. $\left(\mathrm{Sal}_{\mathrm{acl}}{ }^{m}\right.$ ). To relate this product to metal uptake, it is necessary to introduce a coefficient of proportionality $\left(C_{f}\right)$ which relates the activity of the metal ion in the solution to the concentration of the metal in the shrimps. Neglecting the minute amount of metal present in clean organisms, the equation for the concentration of cadmium in the organisms $\left(\mathrm{Cd}_{\text {shrimp }}\right)$ becomes: $\mathrm{Cd}_{\text {shrimp }}=\mathrm{C}_{\mathrm{f}}\left(\mathrm{Cd}^{2+}{ }_{\text {act }}{ }^{k} \cdot \mathrm{Sal}_{\exp }{ }^{1} \cdot \mathrm{Sal}_{\left.{ }_{\mathrm{acl}}{ }^{{ }^{p}}\right)}\right)$. 


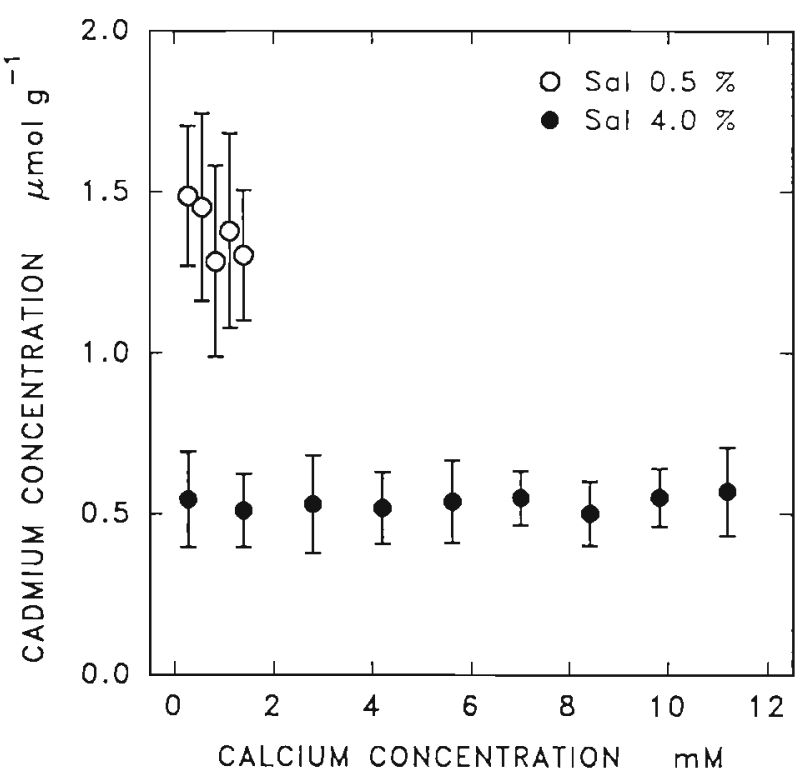

Fig. 8. Artemia franciscana. Effect of calcium at constant salinity of exposure on uptake of cadmium over a $3 \mathrm{~h}$ period for the 0.5 and $4.0 \%$ acclimation groups $\left(\mathrm{Cd}_{\mathrm{T}}=100 \mu \mathrm{M}, \mathrm{pH}=\right.$ 8.0 to $8.2, \mathrm{pO}_{2}=10^{-069} \mathrm{~atm}, \mathrm{pCO}_{2}=10^{-348} \mathrm{~atm}$, solution contains chloride). Means with SD for 5 replicates are not significantly different for both the 0.5 and $4.0 \%$ groups, $p>0.05$

Table 3. Artemia franciscana. Cadmum uptake, pooled data non-linear regression. B: partial regression coefficients, SE: standard error of partial regression coefficients, $L_{1}, L_{2}$ : confidence limits for partial regression coefficients. Activities are in $\mu \mathrm{mol} \mathrm{L}^{-1}$ for cadmium in solution and concentrations in $\mu \mathrm{mol} \mathrm{g}^{-1}$ for cadmium in shrimp

\begin{tabular}{|c|c|c|c|c|}
\hline Variable & B & SE & $L_{1}$ & $\mathrm{~L}_{2}$ \\
\hline \multicolumn{5}{|c|}{ (a) $\mathrm{Cd}_{\text {shrimp }}=C_{1}\left(\mathrm{Cd}^{2+}{ }_{\text {acl }}{ }^{k}\right)\left(\mathrm{R}^{2}=0.578 \cdots, \mathrm{n}=125\right)$} \\
\hline Coefficient & $0.262^{\cdots}$ & 0.087 & 0.089 & 0.435 \\
\hline$k$-exponent & $0.766^{\cdots}$ & 0.097 & 0.573 & 0.959 \\
\hline \multicolumn{5}{|c|}{ (b) $\mathrm{Cd}_{\text {shrimp }}=C_{\mathrm{f}}\left(\mathrm{Cd}^{2+}{ }_{\text {act }}{ }^{k} \cdot \mathrm{Sal}_{\exp }{ }^{j}\right)\left(\mathrm{R}^{2}=0.620^{\cdots}, \mathrm{n}=125\right)$} \\
\hline Coefficient & $0.419 \cdots$ & 0.124 & 0.173 & 0.665 \\
\hline k-exponent & $0.581 \cdots$ & 0.094 & 0.396 & 0.766 \\
\hline l-exponent & $-0.171 \cdots$ & 0.047 & -0.263 & -0.079 \\
\hline \multicolumn{5}{|c|}{ (c) $\mathrm{Cd}_{\text {shrimp }}=C_{\mathrm{i}}\left(\mathrm{Cd}^{2+}{ }_{\mathrm{acl}}{ }^{k} \cdot \mathrm{Sal}_{\mathrm{acl}}{ }^{m \prime}\right)\left(\mathrm{R}^{2}=0.863^{\cdots} \cdot, \mathrm{n}=125\right)$} \\
\hline Coefficient & $0.138 \cdots$ & 0.027 & 0.085 & 0.191 \\
\hline$k$-exponent & $0.866^{\cdots}$ & 0.056 & 0.754 & 0.978 \\
\hline m-exponent & $0.466^{\cdots} \cdot$ & 0.038 & 0.391 & 0.541 \\
\hline \multicolumn{5}{|c|}{$\begin{array}{l}\text { (d) } \mathrm{Cd}_{\mathrm{shrimp}}=C_{\mathrm{f}}\left(\mathrm{Cd}^{2+}{ }_{\text {act }}{ }^{k} \cdot \mathrm{Sal}_{\exp }{ }^{1} \cdot \mathrm{Sal}_{\mathrm{acl}}{ }^{\mathrm{m}}\right)\left(\mathrm{R}^{2}=0.937 \cdots \text {, }\right.\end{array}$} \\
\hline Coefficient & $0.165 \cdots$ & 0.025 & 0.115 & 0.215 \\
\hline k-exponent & $0.571 \cdots$ & 0.036 & 0.500 & 0.642 \\
\hline l-exponent & $-0.338 \cdots$ & 0.015 & -0.367 & -0.309 \\
\hline m-exponent & $0.506 \cdots$ & 0.027 & 0.454 & 0.558 \\
\hline \multicolumn{5}{|c|}{$\cdots 0.01 \geq p>0.001 ; \cdots p \leq 0.001$} \\
\hline
\end{tabular}

Applying this equation, analysis of the pooled results shows that most variation in cadmium uptake is explained when the availability of the metals is determined by the activity of the free metal ion in the solution and that the rate of metal uptake increases with the salinity of acclimation and decreases with the salinity of exposure. Results of the non-linear regression analysis are summarised in Table 3 and Fig 9.

\section{DISCUSSION}

Overall, 3 processes are important in determining the effect of salinity on the uptake of cadmium by brine shrimp. The effect of changes in the activity of the free cadmium ion is important in determining the fraction of the metal in solution which is available for uptake. Acclimation and exposure to different salinities appear important in determining the permeability of the shrimp.

The brine shrimp is an euryhaline hypo-hyperosmotic regulator. Adult shrimp take up water by drinking and excess ions are removed through the gills. The brine shrimp can regulate its internal environment over a very wide range of external conditions. It maintains its internal osmolarity below that of the medium in environments above 250 mosm, but maintains its internal osmolarity above that of the medium at lower levels. This means that the brine shrimp possesses mechanisms for both hyposmotic and hyperosmotic regulation. In hypo-hyperosmotic animals the energetic demands of osmotic regulation may be reduced by lowering the osmotic gradient between organism and environment and by limiting permeabilities to water and salts in dilute environments (Croghan 1958a, b, c).

Within each acclimation group uptake of cadmium in brine shrimp increased with decreasing salinity of exposure. Among the acclimation groups uptake decreased with decreasing salinity of acclimation. Uptake at the salinity of acclimation was maximum at the lowest salinity and minimum at intermediate salinities. The effect of salinity on the uptake of cadmium is therefore the combined result of the effect of the salinity of acclimation on the permeability of the shrimp and the effect of the salinity of exposure on the availability of the metal. However, it is important to recognise that the magnitude of reduction in permeability following transfer to low salinity may be overestimated if the shift in electrical gradient is not taken into account. The trans-epithelial potential of hypoosmotic regulators is strongly negative after transfer of the animal to low salinity. Thus the transfer of cations (influx and efflux) is altered independent of an intrinsic change in permeability (Mantel \& Farmer 1983). 


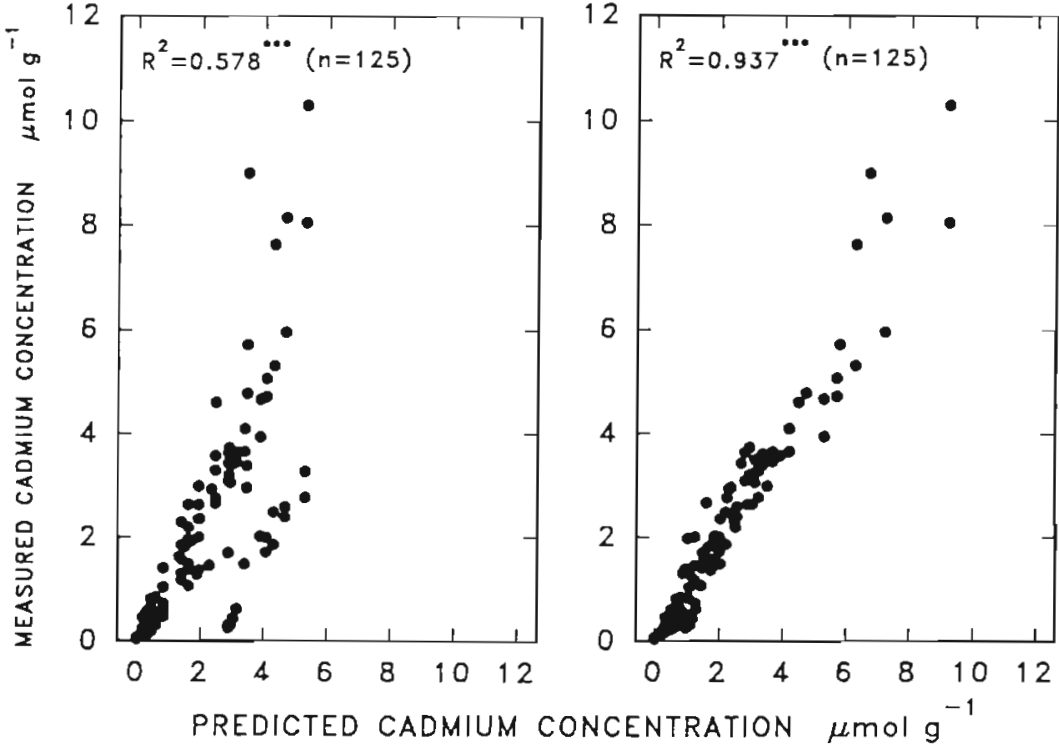

Fig. 9. Artemia franciscana. Predicted versus measured concentrations of cadmium in shrimp for 2 uptake models: (a) $\mathrm{Cd}_{\text {shrimp }}=C_{f}\left(\mathrm{Cd}^{2+}{ }_{\text {act }}{ }^{k}\right), \mathrm{R}^{2}=0.578 \cdots$, $\mathrm{n}=125$ and (b) $\mathrm{Cd}_{\text {shrimp }}=C_{1}\left(\mathrm{Cd}^{2+}{ }_{\mathrm{Art}}{ }^{k} \cdot \mathrm{Sal}_{\mathrm{exp}}{ }^{\prime} \cdot \mathrm{Sal}_{\mathrm{adi}}{ }^{m}\right), \mathrm{R}^{2}=0.937 \cdots, \mathrm{n}=125$ $(\cdots p \leq 0.001)$

The availability of cadmium to the brine shrimp depends on the free cadmium ion level in the solution. Several studies have indicated that the availability of cadmium depends on the free metal ion activity or concentration of the solution (Sunda et al. 1978, Engel \& Fowler 1979, De Lisle \& Roberts 1988). Most of these studies have not experimentally considered the functional difference between these 2 related factors. Present results show that the availability of cadmium depends on the activity rather than on the concentration of the free metal ion. However, since activity and concentration are closely related, the functional difference between these 2 factors is only apparent in the low salinity region where changes in activity and concentration are most pronounced. It has been shown that several other factors which vary with salinity such as the osmolarity (George et al. 1978) and composition (i.e. calcium and magnesium concentration) of the solution influence the uptake or toxicity of cadmium in aquatic organisms (Wright $1977 \mathrm{a}, \mathrm{b}$, Wright \& Frain 1981, Pärt et al. 1985). However, present results indicate that changes in the concentration of the major ions or osmolarity of the solution do not appear to alter the uptake of cadmium to the brine shrimp. Within each acclimation group changes in the activity of the free cadmium ion with changes in the salinity, chlorinity or osmolarity of the solution explain almost all of the variation in cadmium uptake observed. Metal availability is related to the activity rather than the concentration of the free metal ion in the solution because the activity coefficient of a species is a measure of the effectiveness with which it influences an equilibrium in which it is a participant. In freshwater solutions where ionic strength is minimal the activity coefficient approaches unity. Under such circumstances the activity and molarity of a species are almost the same. As the ionic strength increases, however, an ion loses some of its effectiveness and its activity coefficient decreases (Whitfield \& Turner 1979).

The effect of salinity on the availability of cadmium to an aquatic animal should not be directly compared with the effect of salinity on the accumulation or toxicity of cadmium in the animal. The availability of a metal is the fraction of the total concentration in the medium that can be taken up by an animal. The initial step in metal uptake involves the translocation of the metal across the solution-body interface from the external to the internal environment formed by the cells of the exchange surfaces (i.e. gill and gut epithelium). The translocation of the metal across the solution-body interface is considered to be a facilitated process. The transport of the metal from the exchange epithelium to the blood from where it is carried to other parts of the body is considered to be an active process (Verbost et al. 1987. 1988, Foulkes 1989). The apical, basolateral and basal membranes of transporting epithelia are functionally different. Therefore the direct effect of environmental conditions on metal transport across the solution-body interface are not the same as the effects on the other parts of the transport system (Williams 1983).

To explain the effects of environmental processes on the availability, uptake and accumulation of metals it is important to separate these different steps. It is well established that changes in the chemical speciation of the metal (i.e. changes in the activity of the free metal ion) have a direct effect on the translocation of the metal from the external to the internal environment of the epithelium. Changes in the concentration of the major cations (i.e. calcium and magnesium) do not appear to alter the translocation of cadmium across the solution-body interface in brine shrimp. These results seem in contrast with the well-established interactions between calcium and cadmium, which are the result of both divalent cations having similar ionic radii (Williams 1981). There are several mechanisms by which calcium may alter the uptake of metals by aquatic organisms: (1) calcium-dependent changes in the permeability of the epithelial structures, causing a 
decrease in metal uptake as calcium concentration increases; (2) competition for binding sites on the apical membrane surfaces between calcium and divalent metal ions; and (3) decreased metal transfer from the epithelium to the blood with increasing intracellular levels of calcium (Hull 1985, Van Os 1987).

The results concerning the effect of the salinity of acclimation and the composition of the solution do not show a decrease in cadmium uptake with an increase in the concentration of calcium or any of the other major cations. In saltwater animals the effect of calcium and magnesium on metal uptake does not appear to influence metal uptake directly. This is exemplified by several studies dealing with the effect of calcium and magnesium on the uptake, retention and transfer of cadmium in exchange epithelia of aquatic organisms (Pärt \& Svanberg 1981, Pärt et al. 1985, Verbost et al. 1987, 1988). These studies have demonstrated that calcium increases the retention of cadmium in the epithelia and decreases the transfer of cadmium to the blood. Hence it is unlikely to observe an effect of calcium on total metal uptake in short-term studies, where the translocation of the metal across the solution-body interface influx is the most important process. Under these conditions only measurement of the retention of the metal in the epithelia or the transfer of the metal to the blood may reveal an effect of calcium on cadmium transport. It is, however, more likely to observe an effect of calcium on cadmium in more long-term studies of metal toxicity or accumulation where processes such as metal retention and transfer to the blood become more important in determining metal uptake (Pascoe et al. 1986, Wicklund \& Runn 1988, Stephenson \& Mackie 1989).

Acknowledgements. R.B. is a Senior Research Assistant of the National Fund for Scientific Research of Belgium. Hans van Hassel was responsible for maintenance of the brine shrimp culture facility. This work was sponsored by the Fund for Joint Basic Research of Belgium (project 2.0033.90).

\section{LITERATURE CITED}

Baas-Becking, L. G., Kaplan, I. R., Moore, D. (1960). Limits of the natural environment in terms of $\mathrm{pH}$ and oxidation potentials. J. Geol. 68: 243-284

Blust, R., Van der Linden, A., Verheyen, E., Decleir, W. (1988). Evaluation of microwave heating digestion and graphite furnace atomic absorption spectrometry with continuum source background correction for the determination of $\mathrm{Fe}, \mathrm{Cu}$ and $\mathrm{Cd}$ in brine shrimp. J. anal. at. Spectrom. 3: $387-393$

Boyle, E. A., Sclater, F. R., Edmond, J. M. (1976). On the marine geochernistry of cadmium. Nature, Lond. 263: $42-44$

Croghan, P. C. (1958a). The osmotic and ionic regulation of Artemia salina (L.). J. exp. Biol. 32: 219-233
Croghan, P. C. (1958b). The mechanism of osmotic regulation in Artemia salina (L.): the physiology of the branchiae. J. exp. Biol. 35: 234-242

Croghan, P. C. (1958c). The mechanism of osmotic regulation in Artemia salina (L.): the physiology of the gut. J. exp. Biol. 35: 243-249

De Lisle, P. F., Roberts, M. H., Jr, (1988). The effect of salınity on cadmium toxicity to the estuarine mysid Mysidopsis bahia: role of chemical speciation. Aquat. Toxic. 12: $357-370$

Dethlefsen, V. (1978). Uptake, retention and loss of cadmium by brown shrimp (Crangon crangon). Meeresforsch. 26: $137-152$

Dickson, A. G. Whittield, M. (1981). An ion-association model for estimating acidity constants $\left(a t 25^{\circ} \mathrm{C}\right.$ and 1 atm pressure) in electrolyte mixtures related to seawater (ionic strength $1 \mathrm{~mol} \mathrm{~kg}^{-1}$. Mar. Chem. 10: 315-333

Engel, D. W., Fowler, B. A. (1979). Factors influencing cadmium accumulation and its toxicity to marine organisms. Environ. Hith Perspect. 28, 81-88

Foulkes, E. C. (1989). On the mechanism of cellular cadmium uptake. Biol. Trace Element Res. 21: 195-200

George, S. G., Carpene, E., Coombs, T. L. (1978). The effect of salinity on the uptake of cadmium by the common mussel, Mytilus edulis (L.). In: Mclusky, D. S., Berry, A. J (eds.) Physiology and behaviour of marine organisms. Pergamon Press, Oxford, p. 189-193

Gilles, R., Pequeux, A. (1983). Interactions of chemical and osmotic regulation with the environment. In: Bliss, D. E., Vernberg, F. J., Vernberg, W. B. (eds.) The biology of Crustacca, Vol. 8, Environmental adaptations. Academic Press, New York, p. 109-177

Ginzburg, G. (1976). Calculation of all equilibrium concentration in a system of competing complexation. Talanta 23: $142-149$

Glantz, S. A., Slinker, B. K. (1990). Primer of applied regression and analysis of variance. McGraw-Hill, New York

Hull, J. B. (1985). Role of calcium in gill function in freshwater fishes. Comp. Biochem. Physiol. 82A: 543-547

Mantel, L. H., Farmer, L. L. (1983). Osmotic and ionic regulation. In: Bliss, D. E., Mantel, L. H. (eds.) The biology of Crustacea, Vol. 5, Internal anatomy and physiological regulation. Academic Press, New York, p. $53-161$

Mantoura, R. F. C., Dickson, A., Riley, J P. (1978). The complexation of metals with humic materials in natural waters. Estuar. coast. Shelf Sci. 6: 387-408

Martell, A. E., Smith, R. M. (1982). Critical stability constants, Vol. 5, 1st suppl. Plenum Press, New York

Millero, F. J., Schreiber, D. R. (1982). Use of the ionic components of natural waters. Am. J. Sci. 282: 1508-1540

Millero, F. J. (1986). The $\mathrm{pH}$ of estuarine waters. Limnol. Oceanogr. 31. 839-847

Nriagu, J. O. (1988). A silent epidemic of environmental metal poisoning? Environ. Pollut. 50: 139-161

Nriagu, J. O., Pacyna, J M. (1988). Global contamination of air, water and soils with trace metals. Nature, Lond. 333: $134-139$

Pärt, P., Svanberg, O. (1981). Uptake of cadmium in perfused rainbow trout (Salmo gairdneri) gills. Can. J. Fish. Aquat. Sci. 38: $917-924$

Pärt, P., Svanberg, O., Kiessling, A. (1985). The availability of cadmium to perfused rainbow trout gills in different water qualities. Water Res. 19: 427-434

Rainbow, P. S. (1985). Accumulation of $\mathrm{Zn}, \mathrm{Cu}$ and $\mathrm{Cd}$ by crabs and barnacles. Estuar. coast. Shelf Sci. 21. 669-686

Pascoe, D., Evans, S. A., Woodworth, J. (1986). Heavy metal 
toxicity to fish and the influence of water hardness. Arch. environ. Contam. Toxicol. 15: 481-487

Slavin, W., Carnrick, G. R., Manning, D. C. (1983). Recent experiences with the stabilized platform furnace and zeeman background correction. At. Spectrosc. 4: 69-86

Smith, R. M., Martell, A. E. (1976). Critical stability constants, Vol. 4, Inorganic ligands. Plenum Press, New York

Smith, R. M, Martell, A. E. (1989). Critical stability constants, Vol. 6. 2nd suppl. Plenum Press, New York

Sokal, R. R., Rohlf, F. J. (1981). Biometry. Freeman, San Francisco

Sorgeloos, P., Bossuyt, E., Lavens, P., Lèger, P., Vanhaecke, P., Versichele, D. (1983). The use of brine shrimp Artemia in crustacean hatcheries and nurseries. In: McVey, J. P. (ed.) Handbook of mariculture, Vol. 1. CRC Press, Boca Raton, p. $71-96$

Sunda, W. G., Engel, D. W., Thuotte, R. M. (1978). Effect of chemical speciation on toxicity of cadmium to grass shrimp, Palaemonetes pugio: importance of free cadmium ion. Environ. Sci. Technol. 12: 409-413

Stephenson, M., Mackie, G. L. (1989). A laboratory study of the effects of waterborne cadmium, calcium, and carbonate concentrations on cadmium concentrations in Hyalella azteca (Crustacea: Amphipoda). Aquat. Toxic. 15: 53-62

Turner, D. R., Whitfield, M. Dickson, A. G. (1981). The equilibrium speciation of dissolved components in freshwater and seawater at $25^{\circ} \mathrm{C}$ and 1 atm pressure Geochim. Cosmochim. Acta 45: 855-881

Van den Berg, C. M. G., Kramer, J. R. (1979). Determination of complexing capacities of ligands in natural waters and conditional stability constants of the copper complexes by means of manganese dioxide. Analytica chim. Acta 106: $113-120$

Van Os, C. H. (1987). Transcellular calcium transport in intestinal and renal epithelial cells. Biochim. Biophys. Acta 906: 195-222

This article was submitted to the editor
Verbost, P. M., Flik, G., Lock, R. A. C., Wendelaar Bonga, S. E. (1987). Cadmium inhibition of Ca2+ uptake in rainbow trout gills. Am. J. Physiol. 253: R216-R221

Verbost, P. M., Flik, G., Lock. R. A. C., Wendelaar Bonga, S. E. (1988). Cadmium inhibits plasma membrane calcium transport. J. Membrane Biol. 102: 97-104

White, S. L., Rainbow, P. S. (1982). Regulation and accumulation of copper, zinc and cadmium by the shrimp Palaemon elegans. Mar. Ecol. Prog. Ser. 8: 95-101

White, S. L., Rainbow, P. S. (1986). Accumulation of cadmium by Palaemon elegans (Crustacea: Decapoda). Mar. Ecol. Prog. Ser. 32: 17-25

Whitfield, M., Turner, D. R. (1979). Critical assessment of the relationship between biological thermodynamic and electrochemical availability. In: Jenne, E. A. (ed.) Chemical modelling in aqueous solutions. American Chemical Society Symposium Series 93, Washington, D.C., p. $657-680$

Wicklund, A., Runn, P. (1988). Calcium, effects on cadmium uptake, redistribution, and elimination in minnows, phoximus phoximus, acclimated to different calcium concentrations. Aquat. Toxic 13: 109-122

Williams, R. J. P. (1981). Physio-chemical aspects of inorganic element transfer through membranes. Phil. Trans. R. Soc B294: $57-74$

Williams, R. J. P. (1983): Inorganic elements in biological snare and time. Pure appl. Chem. 55: 1089-1100

Wright, D. A. (1977a). The effect of salinity on cadmium uptake by the tissues of the shore crab Carcinus maenas J. exp. Biol. 67: 137-146

Wright, D. A. (1977b). The effect of calcium on cadmium uptake by the shore crab Carcinus maenas. J. exp. Biol. 67: $163-173$

Wright, D. A., Frain, J. W. (1981). Cadmium toxicity in Marinogammarus obtusatus: effect of external calcium. Environ. Res. 24: 338-344

Manuscript first received: January 16, 1992

Revised version accepted: June 4, 1992 